\title{
A STUDY ON COMPARISON OF RESULTS OF PROXIMAL FEMORAL NAIL AND DHS IN UNSTABLE PROXIMAL FEMORAL FRACTURES
}

\author{
Himanshu Bajpai ${ }^{1}$, Sanjeev Kumar Singh², Pankaj Gupta ${ }^{3}$
}

${ }_{1}^{1}$ Assistant Professor, Department of Orthopaedics, Rama Medical College, Kanpur, Uttar Pradesh, India.

${ }^{2}$ Assistant Professor, Department of Orthopaedics, Rama Medical College, Kanpur, Uttar Pradesh, India.

${ }_{3}^{3}$ Senior Resident, Department of Orthopaedics, Rama Medical College, Kanpur, Uttar Pradesh, India.

\section{ABSTRACT}

\section{BACKGROUND}

To compare the functional outcome of patients of unstable proximal femoral fractures treated using either DHS or proximal femoral nail.

\section{MATERIALS AND METHODS}

A randomized, comparative and prospective study was conducted in orthopaedic department of Rama Medical College, Mandhana, Kanpur. 120 patients were included in the study with complete 18 months follow up. They were randomized equally in to two groups (60 patients in each, group 1 for proximal femoral nail and group 2 for dynamic hip screw).

\section{RESULTS}

Incidence of post-operative hip pain in proximal femoral nail group was slightly higher but was not significant. Early mobilization in the post-operative period, of patients, in both groups resulted in less systemic complications. Over long-term follow-up there was no significant difference in the functional outcome in Proximal Femoral Nail \& DHS group ( $p<0.001)$. Mean time of radiological union was similar in both methods of fixation (8.02 \pm 2.1$)$ wks., in proximal femoral nail and $7.93 \pm 1.97$ wks. in DHS group.

\section{CONCLUSION}

The functional outcome by Harris Hip Score at 6 weeks is poor in both groups \& in 3 months, fair in both groups. In 6 months, 12 months and 18 months showed no significant difference between both the groups.

\section{KEY WORDS}

Comparison, Dynamic Hip Screw, Proximal Femoral Nail (PFN), Unstable Proximal Femoral Fracture.

HOW TO CITE THIS ARTICLE: Bajpai H, Singh SK, Gupta P. A study on comparison of results of proximal femoral nail and DHS in unstable proximal femoral fractures. J. Evolution Med. Dent. Sci. 2019;8(07):441-446, DOI: 10.14260/jemds/2019/97

\section{BACKGROUND}

Majority of proximal femoral fractures occur in older age groups and are three times as common in elderly females compared to males. Proximal femoral fractures in younger individuals are the result of high energy injury. In Intertrochanteric fractures approximately $50 \%$ fractures are unstable.[1]

The pathophysiology of proximal femoral fractures is of increased fragility of the osteoporotic bone associated with decreased muscle tone.[2] Osteomalacia due to decreased intake of calcium or vitamin D and lack of ambulation. ${ }^{[2,3]}$

Stability of the fracture is governed by contact between the proximal and distal main fragments. Unstable proximal femoral fractures typically have comminution of posteromedial buttress (Especially when more than $50 \%$ of the calcar is affected) and/or subtrochanteric extension. In 3part fractures stability is inversely proportional to the size of the lesser trochanter. Sometimes the greater and lesser trochanter are separate fragments (4-part fracture). Reverse oblique is a special type of subtrochanteric fracture. ${ }^{[4,5]}$

'Financial or Other Competing Interest': None.

Submission 25-11-2017, Peer Review 01-02-2019,

Acceptance 09-02-2019, Published 18-02-2019.

Corresponding Author:

Dr. Sanjeev Kumar Singh,

26 B, Jawahar Puram,

Shyamnagar, Kanpur-208015,

Uttar Pradesh, India.

E-mail: sanjeev23021985@gmail.com

DOI: $10.14260 /$ jemds $/ 2019 / 97$

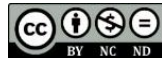

Where instability is actually a function of implant fixation whereby DHS fixation often fails due to fracture line orientation and resulting forces.

Stable reduction of an unstable proximal femoral fracture entails providing medial and posterior cortical contact between the major proximal and distal fragment. Various internal fixation devices like dynamic hip screw (DHS), proximal femur nail (PFN), femoral Reconstruction nail, Trochanteric Femur Nail (TFN) and proximal femur locking compression plate (PF-LCP) are now available for the treatment of essentially all proximal femoral fracture.[6] Internal fixation techniques alleviate pain and permit early ambulation. The available evidence supports the sliding hip screw as the gold standard for fixation of a unstable trochanteric fracture against which other methods of fixation are often compared. This method provides satisfactory stability and positioning of the fragments providing controlled collapse of cancellous bone.[7] Cephalomedullary nails are less preferred because of the associated complications like malunion and backing out of screws. ${ }^{[7]}$ Functional outcome regarding the use of dynamic hip screw for fixation of unstable proximal femur fracture was evaluated previously in literature. Functional outcome regarding the use of proximal femoral nail was retrospectively evaluated by many orthopaedic groups recently in literature. Adams et al[8] concluded that Use of the Gamma nail was associated with a higher risk of postoperative complication in comparison to dynamic hip screw. Harrington et al[9] in a similar prospective randomized trial comparing intramedullary hip screw (IMHS) to dynamic 
hip screw reported no difference between the two groups with respect to radiological or functional outcome. We performed a study to primarily compare the functional outcome in a prospective randomized manner for fixation of unstable proximal femoral fractures using dynamic hip screw and proximal femoral nail. We also studied the radiological outcome and complications of the two fixation methods.

\section{Aim of The Study}

To compare the functional outcome of the two fixation methods PFN and DHS in unstable proximal femur fractures.

\section{MATERIALS AND METHODS}

\section{Type of Study}

Randomized, comparative and prospective study.

\section{Setting \& Design}

This study was conducted in Orthopaedic department of RAMA Medical College Mandhana, Kanpur from August 2014 to February 2016 in this period patient operated and thereafter followed up for 18 months after the date of surgery. All patients with unstable fresh proximal femoral fractures admitted in the department have been considered for the study. Patients were randomized into two groups (One for fixation with proximal femoral nail (Group 1) and other with DHS (Group 2)

\section{Sample Size}

Sample size was decided as per our convenience by following the inclusion and exclusion criteria.

\section{Inclusion Criteria}

All patients with unstable proximal femoral fracture (Boyd and griffins' type 3 and type 4) who will be admitted to the department of the Orthopaedics at RAMA Medical College Mandhana, Kanpur and fit for surgery were included in study after randomization.

\section{Exclusion Criteria}

- Patients with stable trochanteric fracture.

- Patients with un-operable fractures viz. having bed sores precluding fixation, too debilitated, bed-ridden due to hemi paresis etc., Polytrauma patients,

- Patients treated conservatively due to any medical reasons, Pathological fracture and fracture of paediatric age group.

- Patients without complete 18 month follow up excluded.

\section{Tools}

1. Randomization done by http.startrek.com/table/ random.aspx on the basis of admission of patients in emergency ward with surgical procedure only.

2. Unstable proximal femur fracture considered for study on the basis of Boyd and Griffin's classification.

3. Harris hip scoring used for functional outcome at certain intervals.

4. Follow-up patients by telephonic calling for radiological as well as functional outcomes till 18 months pass after the date of surgery.

\section{Statistical Analysis}

Analysis was conducted using IBM SPSS statistics (version 22.0). Statistical Analysis is done by using Chi square test, means of 2 continuous normally distributed variables were compared by independent samples, Student's t-test.

\section{RESULTS}

Table no. 1 shows the demographic profile of study subjects in both the groups. In this study total 120 patients are included, $50.0 \%$ males and $50.0 \%$ females. 106 out of 120 patients were above 50 year of age and only 14 patients were below 50 years. The average age in this study for PFN group was 66.91 and for DHS group 67.40 years with (Max 90 years/min 44 years). All unstable proximal femoral fracture which were consider for evaluation belongs to Boyd and Griffin's type 3 and type 4 . Type 3 fractures were $52.50 \%$ and types 4 were $47.50 \%$. Males ( $\mathrm{PFN}=60 \%$; $\mathrm{DHS}=40 \%$ ) are more affected in PFN group and females (PFN=45\%; DHS=55\%) are more affected in DHS group. Maximum fractures (73.3\%) due to simple slip on ground and fall from stairs. Followed by fall from height men $15.0 \%$ and female were $20.0 \%$. Fracture due to road traffic accidents was more common among young males was $26.7 \%$ and female $13.3 \%$. In DHS group right side was affected in $56.7 \%$ cases and left side in $43.3 \%$ cases. Whereas in PFN group it was $48.3 \%$ in right side and $51.7 \%$ in left side.

Duration of union radio logically (Three out of four cortices in two perpendicular views) in proximal femoral nail group was 8.02 \pm 2.1 wks., and in DHS group was $7.93 \pm 1.97$ wks. [Table-2]. Mean Harris hip score in proximal femoral nail group at 6 weeks was $48.3 . \pm 12.8$ as compared to $47.82 \pm$ 9.74 for DHS group. This is considered poor in both groups Mean Harris hip score in proximal femoral nail group at 3 months was $66.16 \pm 12.8$ as compared to $71.93 \pm 8.18$ for DHS group. This is considered fair in both groups [Figure-1 \& 2] Mean Harris hip score in proximal femoral nail group at 6 months was $81.85 \pm 7.36$ as compared to $82.62 \pm 5.71$ for DHS and proximal femoral nail group at 18 months was 87.30 \pm 4.7 as compared to $90.2 \pm 2.2$ this is considered good in both groups [Table-3]. In this study no patients had postoperative surgical site infection. Ten-degree flexion deformity in two patient of DHS group. Two patients in proximal femoral nail group had screws pull out and one patient had broken nail. No patients have nerve palsy in both the groups. Complain of pain in hip /knee sixteen patients in DHS group and twenty patients in PFN group. [Table-4].

\begin{tabular}{|c|c|c|c|c|c|c|}
\hline Variables & \multicolumn{6}{|c|}{ Type of Surgery } \\
\hline $\begin{array}{c}\text { Age (Age in } \\
\text { Years) }\end{array}$ & $\begin{array}{c}\text { PFN } \\
(n=60)\end{array}$ & $(\%)$ & $\begin{array}{c}\text { DHS } \\
(n=60)\end{array}$ & $(\%)$ & Total & $\begin{array}{c}\text { p- } \\
\text { Value }\end{array}$ \\
\hline $41-50$ & 5 & 8.3 & 2 & 3.3 & 7 & \multirow{5}{*}{0.823} \\
\hline $51-60$ & 7 & 11.7 & 14 & 23.3 & 21 & \\
\hline $61-70$ & 24 & 40.0 & 23 & 38.3 & 47 & \\
\hline $71-80$ & 20 & 33.3 & 15 & 25.0 & 35 & \\
\hline $81-90$ & 4 & 6.7 & 6 & 10.0 & 10 & \\
\hline \multicolumn{7}{|c|}{ Sex } \\
\hline Male & 36 & 60 & 24 & 40 & 60 & \multirow[b]{2}{*}{0.643} \\
\hline Female & 27 & 45 & 33 & 55 & 60 & \\
\hline \multicolumn{7}{|c|}{ Mode of Injury } \\
\hline Slip and Fall & 35 & 65 & 40 & 73.3 & 75 & \multirow{3}{*}{0.082} \\
\hline Fall from height & 9 & 15 & 12 & 20.0 & 21 & \\
\hline \begin{tabular}{c|} 
RTA \\
\end{tabular} & 16 & 26.7 & 8 & 13.3 & 24 & \\
\hline \multicolumn{7}{|c|}{ Side Affected } \\
\hline Right Side & 29 & 48.3 & 34 & 56.7 & 63 & \multirow[b]{2}{*}{0.59} \\
\hline Left Side & 31 & 51.7 & 26 & 43.3 & 57 & \\
\hline Table 1. Demc & aphic & $\begin{array}{r}\text { Profile } \\
\text { Gro }\end{array}$ & Stud & ubje & 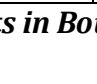 & th the \\
\hline
\end{tabular}




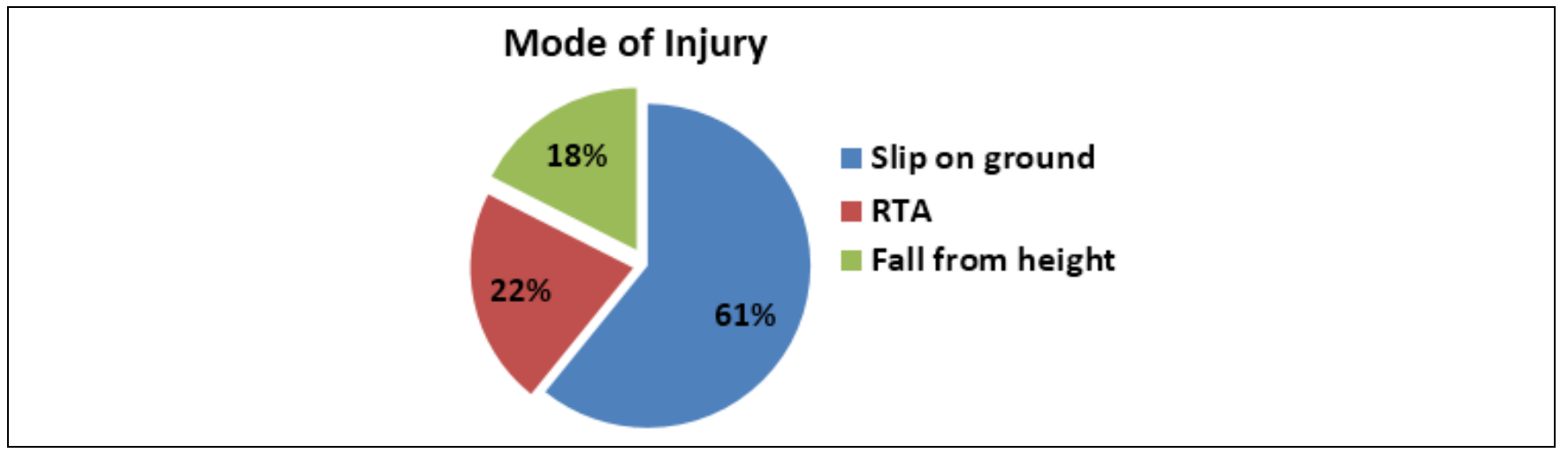

\begin{tabular}{|c|c|c|}
\hline Procedure & Mean + S.D. & p-Value \\
\hline PFN Mean Union Time (weeks) & $8.02 \pm 2.1$ & \multirow{2}{*}{ p $<0.001$} \\
\hline DHS Mean Union Time (weeks) & $7.93 \pm 1.97$ & \\
\hline \multicolumn{2}{|c|}{ Table 2. Mean Duration of Union Time } \\
\hline
\end{tabular}

\begin{tabular}{|c|c|c|c|}
\hline & PFN (Mean Harris Hip Score) & DHS (Mean Harris Hip Score) & p-Value \\
\hline At 6 Weeks & $48.23 \pm 12.8$ & $47.82 \pm 9.74$ & 0.09 \\
\hline At 3 Months & $66.16 \pm 12.8$ & $71.93 \pm 8.8$ & 0.014 \\
\hline At 6 Months & $81.85 \pm 7.36$ & $82.62 \pm 5.71$ & 0.05 \\
\hline At 12 Months & $84.8 \pm 6.0$ & $87.3 \pm 4.7$ & 0.0012 \\
\hline At 18 Months & $86.5 \pm 3.6$ & $90.2 \pm 2.2$ & 0.001 \\
\hline \multicolumn{4}{|c|}{ Table 3. Mean Harris Hip Score } \\
\hline
\end{tabular}

\begin{tabular}{|c|c|c|c|}
\hline & Mean Harris Hip Score \\
\hline & & & \\
\hline & & & \\
\hline
\end{tabular}

\begin{tabular}{|c|c|c|}
\hline Complication of Surgery & DHS & PFN \\
\hline Infection & - & - \\
\hline Mechanical Failure of Implant & 2 & 6 \\
\hline Pain in Hip, Knee & 16 & 20 \\
\hline Nerve Palsy (CPN/Sciatic Nerve) & - & - \\
\hline Deformity /Non-Union & 2 & - \\
\hline Table 4. Complications of Surgery
\end{tabular}

Complication of surgery




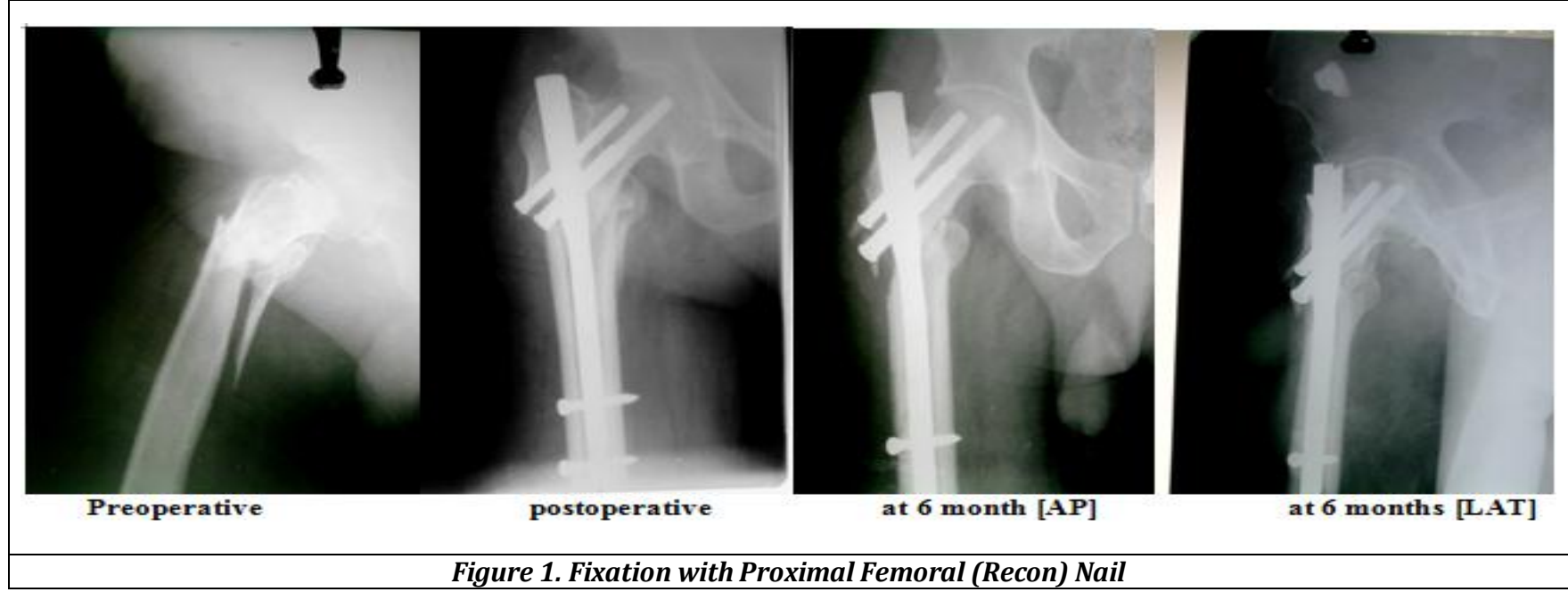

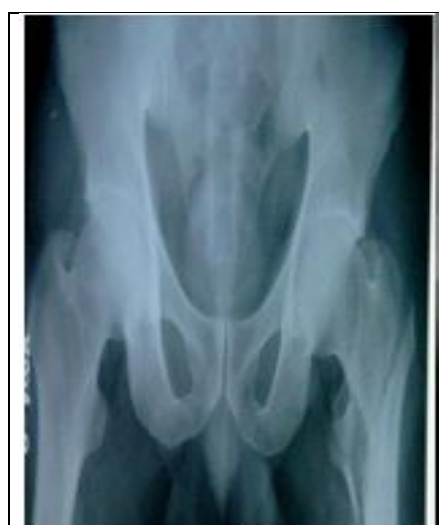

preoperative

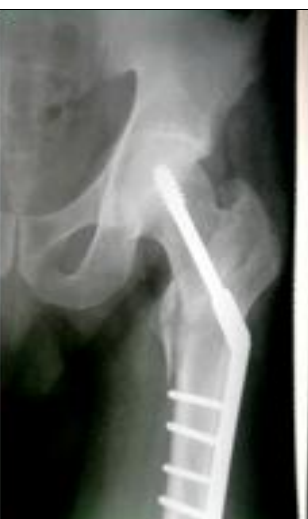

post-operative

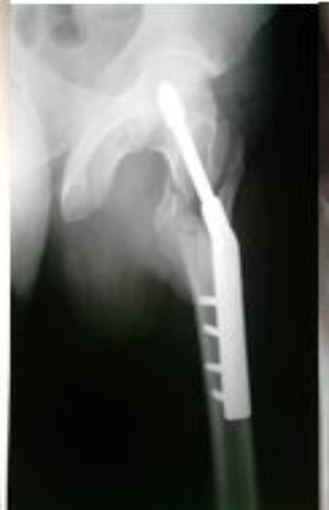

Figure 2. Fixation with Dynamic Hip Screw

\section{DISCUSSION}

Proximal femoral fractures are a common injury in osteoporotic elderly males and females.[1,2,10] Various implants are available for fixation of unstable fractures and in a typical setting the choice rests on choosing from dynamic hip screw or proximal femoral nail.[1,3] Being the most commonly used fixation devices we chose to study if there is any difference between them primarily based on functional outcome (using Harris hip score). Patients with unstable proximal femoral fractures who were operated by using either DHS or proximal femoral nail in RAMA Medical College Kanpur from august 2014 to February 2016 were followed up and functional outcome assessed by Harris Hip Score by the guidelines discussed previously.

In our study males and females were equally distributed. Melton et al[2] reported female to male ratio is $3: 1$ in their study. Our findings may be because road traffic accident is more common in males. ${ }^{[3,4]}$ Male patients are more likely to turn up for follow up studies because of the fact that male patients are more independent. The female population is more restricted and dependent for social and cultural reasons. Dynamic hip screw osteosynthesis in unstable fractures was associated to a higher incidence of complications.[11]

There were many recommendations for fixation of unstable proximal femur fracture using newer intra medullary devices. ${ }^{[12,13,14]}$

There was no difference in the average Harris hip scores
(HHS) at 18-month follow-up in the two groups in our study also ( $p$ <.001). Average Harris Hip Score in both the internal fixation groups was categorized poor till one and half months. Average Harris hip score at three months and was categorized good both in DHS and proximal femoral nail group. Hardy et al [6] performed a prospective, randomized study comprising use of a sliding hip screw to an intramedullary hip screw in 100 patients. All patients were above 60 years of age. Operative time was significantly greater for the intramedullary device ( $p$-value $>0.07)$; estimated intra operative blood loss ( $p$-value>0.011), however, was significantly lower. Intra operative greater trochanter fracture and shaft fracture was preferentially treated with intra medullary fixation. They found that patients using the intramedullary hip screw experienced better mobility at 1 - and 3-months follow-up ( $p$ value $<0.014$ ). compared to dynamic hip screw. Mobility at 6 months followup also had no difference ( $\mathrm{p}$ value $<0.05$ ). The in-hospital and 6-month mortality rates were similar for the two treatment groups. Although patients who received the intramedullary device enjoyed significantly better walking ability outside the home at all time periods. The intramedullary hip screw was associated with significantly less screw sliding (p-value $<0.012$ ) and limb shortening than the sliding hip screw, particularly when used to stabilize unstable fracture patterns.

Adams et al in their prospective randomized study comparing a sliding hip screw to an intramedullary nail for 
treatment of Intertrochanteric fractures compared 203 patients were stabilized with a short Gamma nail while 197 received a sliding hip screw. Patients were followed for 1 year. Use of the Gamma nail (Intra medullary nail) was associated with a higher risk of postoperative complications in their study.[9] Harrington et al performed a similar prospective randomized trial comparing use of the intra medullary hip screw (IMHS) to a sliding hip screw for the treatment of unstable Intertrochanteric fractures. 52 patients were stabilized using the sliding hip screw and 50 with the IMHS. At 1-year follow-up, there was no difference between the two groups with respect to radiological or functional outcome. Bienkowski et al compared the results of unstable trochanteric fracture with a new nail device, TFN (trochanteric fixation nail) with DHS. They observed no complication occurred with TFN.[15,16] Comparison of the surgical complications and functional outcome of the intra medullary fixation device versus DHS in unstable proximal femoral fractures. They recommended use of the intra medullary device in unstable fracture over the current standard treatment of dynamic hip screw and plate.[17,18,19,11]

It is evident from the studies that the comparative results of intra medullary hip screws and dynamic hip screws reveal no significant differences with respect to implant failure and screw cut-out and that there is evidence for each of the studied parameters on either side by different authors. [7,9,15] Though there is some support for proximal femoral nail in terms of operative time and blood loss. $[6,18,11,20]$ there is increased risk for femoral shaft fracture at the nail tip and the insertion sites of the distal locking screws. [9,21]

In our study we also did not found any difference in functional outcome for fractures fixed with DHS and proximal femoral nail, so we could not predict the superiority of one implant over other.

In our study the mean union time was $8.02 \pm 2.1$ weeks in proximal femoral nail group after which weight bearing was allowed as compared to $7.93 \pm 1.97$ weeks in DHS group. There was one failure of fixation found in DHS group but three patients in proximal femoral nail group. Menezes et al (2005) [22] reviewed 155 consecutive patients who were treated with a proximal femoral nail from 1997 to 2001 to determine the rate of implant specific complications. One year postoperative follow up was available for 129 of 132 surviving patients (98\%). Failure of fixation occurred in three patients $(2 \%)$, and a femoral shaft fracture occurred in one patient $(0.7 \%)$. The total reoperation rate was high $(12 \%)$ mainly because of hardware removals, which occurred in 13 patients $(8.6 \%)$.

In our study the complications in the form of mild hip and knee pain occurred in both groups. There was no failure of DHS fixation however one nail breakage was seen in proximal femoral nail. This bias for major complications could be truly attributed to limited number of cases and no significance could be drawn from the finding.

\section{CONCLUSION}

DHS plate and proximal femoral nail are two implants which are used extensively for fixation of unstable proximal femoral fracture with equal convenience. Incidence of post-operative hip pain in proximal femoral nail group was slightly higher but not significant. Early mobilization in the post-operative period of patients in both groups resulted in less systemic complications such as pneumonia, pulmonary emboli due to DVT, bed sores and joint stiffness. Over long-term follow-up, there was no significant difference in the functional outcome in proximal femoral nail \& DHS group. Mean time of radiological union was similar in both methods of fixation $(8.02 \pm 2.1$ wks. in proximal femoral nail and $7.93 \pm 1.97 \mathrm{wks}$. in DHS group). Since both DHS and proximal femoral nail have got satisfactory functional outcome in long term follow up of up to 18 months, we recommend both as implants of choice for unstable proximal femoral fractures. Physiotherapy is an integral part of proximal femoral fracture management \& co-operation is required on the part of the patient. Inadequate physiotherapy results in poor outcome due poor gain of movements.

\section{Limitations}

Comparative study conducted in private institute with limited number of patients and catering to rural population with limited resources of management. More high-quality randomized controlled trials are needed to evaluate data for better outcome.

\section{REFERENCES}

[1] Rockwood CA Jr, Green DP, Bucholz RW. Rockwood \& Green's Fractures in adults. Section - 4. Chapter - 45. In: Bucholz RW, Heckman JD, Court-Brown CM, et al. eds. Lower extremity > Intertrochanteric fractures. Vol. 2. $6^{\text {th }}$ edn. Philadelphia: Lippincott Williams \& Wilkins c2006.

[2] Melton LJ 3rd, Ilstrup DM, Riggs BL, et al. Fifty year trend in hip fracture incidence. Clin Orthop Relat Res 1982;162:144-9.

[3] Koval KJ, Aharonoff GB, Rokito AS, et al. Patients with femoral neck and intertrochanteric fractures. Are they the same? Clin Orthop Relat Res 1996;330:166-72.

[4] Hayes WC. Biomechanics of falls and hip fracture in the elderly. In: Apple DF, Hayes WC, eds. Prevention of falls and hip fractures in the elderly. Rosemont, Illinois: American Academy of Orthopaedic Surgeons 1994: p. 41-65.

[5] Cummings SR, Nevitt MC. A hypothesis: the causes of hip fractures. J Gerontol 1989;44(4):107-11.

[6] Hardy DC, Descamps PY, Krallis P, et al. Use of an intramedullary hip-screw compared with a compression hip-screw with a plate for Intertrochanteric femoral fractures. A prospective, randomized study of one hundred patients. J Bone Joint Surg 1998;80(5):618-30.

[7] AL-Yassari G, Langstaff RJ, Jones JW, et al. The AO/ASIF Proximal Femoral Nail (PFN) for the treatment of unstable trochanteric femoral fracture. Injury 2002;33(5):395-9.

[8] Adams CI, Robinson CM, Court-Brown CM, et al. Prospective randomized controlled trial of an intramedullary nail versus dynamic screw and plate for intertrochanteric fractures of the femur. J Orthop Trauma 2001;15(6):394-400.

[9] Harrington $P$, Nihal A, Singhania AK, et al. Intramedullary hip screw versus sliding hip screw for intertrochanteric femoral fractures in the elderly. Injury 2002;33(1):23-8. 
[10] Singh M, Nagrath AR, Maini PS. Changes in trabecular pattern of the upper end of the femur as an index of osteoporosis. J Bone Joint Surg (Am) 1970;52(3):45767.

[11] Taeger G, Schmid C, Zettl R, et al. Stable and unstable pertrochanteric femoral fractures. Differentiated indications for the dynamic hip screw. Unfallchirurg 2000;103(9):741-8.

[12] Müller M, Seitz A, Besch L, et al. Proximal femur fractures: results and complications after osteosynthesis with PFN and TGN. Unfallchirurg 2008;111(2):71-7.

[13] Anjum MP, Hussain FN, Mehboob I. Treatment of intertrochanteric femoral fractures with a proximal femoral nail (PFN): a short follow up. Nepal Med Coll J 2009;11(4):229-31.

[14] Chou DT, Taylor AM, Boulton C, et al. Reverse oblique intertrochanteric femoral fractures treated with the Intramedullary Hip Screw (IMHS). Injury 2012;43(6):817-21.

[15] Sadowski C, Lubbeke A, Saudan M, et al. Treatment of reverse oblique and transverse Intertrochanteric fractures with use of an intramedullary nail or a 95 degree screw-plate: a prospective, randomized study. J Bone Joint Surg 2002;84-A(3):372-81.

[16] Bienkowaski P, Reindl R, Berry GK, et al. A new intramedullary nail device for the treatment of intertrochanteric hip fractures: perioperative experiences. J Trauma 2006;61(6):1458-62.
[17] Klinger HM, Baums MH, Eckert M, et al. A comparative study of unstable per and intertrochanteric femoral fractures treated with Dynamic Hip Screw (DHS) and trochanteric butt-press plate vs. Proximal Femoral Nail (PFN). Zentralbl Chir 2005;130(4):301-6.

[18] Bridle SH, Patel AD, Bircher $M$, et al. Fixation of intertrochanteric fractures of the femur. A randomized prospective comparison of the gamma nail and the dynamic hip screw. J Bone Joint Surg $\mathrm{Br}$ 1991;73(2):330-4.

[19] Babhulkar SS. Management of trochanteric fractures. IJO 2006;40(4):210-8

[20] Knobe M, Münker R, Sellei RM, et al. Unstable pertrochanteric femur fractures. Failure rate, lag screw sliding and outcome with extra and intramedullary devices (PCCP, DHS and PFN). Z Orthop Unfall 2009;147(3):306-13.

[21] Kamboj P, Siwach R, Kundu Z, et al. Results of modified proximal femoral nail in peritrochanteric fractures in adults. The Internet Journal of Orthopedic Surgery 2007;6(2):1-6.

[22] Menezes DF, Gamulin A, Noesberger B. Is the proximal femoral nail a suitable implant for treatment of all trochanteric fractures? Clin Orthop Relat Res 2005;439:221-7. 